\title{
Assessment of the 2006 to 2015 Corvara landslide evolution using a UAV-derived DSM and orthophoto
}

\author{
B. Thiebes, E. Tomelleri, A. Mejia-Aguilar, M. Rabanser \& R. Schlögel \\ Institute for Applied Remote Sensing, European Academy of Bozen/Bolzano (EURAC), Italy \\ M. Mulas \& A. Corsini \\ Department of Chemical and Geological Sciences, University of Modena and Reggio Emilia, Modena, Italy
}

\begin{abstract}
We present a UAV-based photogrammetry study on Corvara landslide, a large and active earthflow in the Italian Dolomites. During a one-day field survey, an area of approximately 13 ha was covered and a very high resolution orthophoto and a point cloud consisting of more than 200 million points were created. From this data, a Digital Surface Model (DSM) with a pixel size of $1.5 \mathrm{~cm}$ was prepared. The comparison to the existing 2006 LiDAR DSM highlights landslide enlargements, displacement rates and material depletion and accumulation exceeding $11 \mathrm{~m}$. Although some uncertainties regarding the exact magnitude of topographical changes remain, the methodology has been evaluated as a useful addition to the ongoing monitoring activities on the Corvara landslide by GPS and DInSAR due to the unprecedented level of detail.
\end{abstract}

\section{INTRODUCTION}

In recent years, several techniques have increased the potential use of remotely sensed data for the mapping and monitoring of landslides (Delacourt, 2004; Guzzetti et al., 2012; Jaboyedoff et al., 2010). Among numerous improvements in sensor technology and methods, several advances stand out in the fields of ground-based, airborne and space-borne remote sensing. Launches of new generations of optical (e.g. Geoeye-1, WorldView-2, Pleiades 1A\&1B, SPOT5, 6\&7, Formosat-2 and Kompsat-2, Sentinel-2) and radar (e.g. TerraSAR-X, Cosmo-Skymed, Sentinel-1) satellites with short repeat-pass cycle and high spatial resolutions are expected to result in better capabilities to acquire data over wide areas shortly after major landslide triggering events and to monitor them at regular intervals. Ground-Based Synthetic Aperture Radar (GB-SAR) as well as Light Detection And Ranging (LiDAR) are also commonly used to examine the landslide morphologies and movement rates.

Unmanned Aerial Vehicles (UAVs) have become more affordable and are more frequently being used in geosciences. UAV campaigns using digital photography are able to acquire point clouds of surface features which can be processed to obtain digital terrain models of centimetre resolution.

In this paper, we present an analysis of the landslide for parts of the Corvara landslide. We used a UAV to acquire digital photographs which were processed to a point cloud and a Digital Surface Model (DSM). These were then compared to existing data sets to assess the changes over time.

\section{STUDY AREA}

Corvara landslide is a complex earth slide-earth flow located above the tourist town of Corvara in Badia, Italy (Figure 1A). The landslide has been investigated extensively over the past years, including studies on landslide characterisation and fieldbased monitoring (Corsini et al., 2005), event dating (Borgatti and Soldati, 2010), scenario modelling (Schädler et al., 2014), and satellite-based multitemporal interferometry monitoring (Mulas et al., 2015). The current monitoring set-up (Figure 1B) includes regular and permanent GPS measurements, as well as several corner reflectors for satellite-based radar monitoring. Corvara landslide has a total volume of more than 30 million $\mathrm{m}^{3}$, a length of $3.5 \mathrm{~km}$, a depth of up to $100 \mathrm{~m}$ and has been active for more than 10,000 years. The presently active part of the landslide involves approximately 25 million $\mathrm{m}^{3}$; with major active shear surfaces ranging between 10 and $48 \mathrm{~m}$. Ongoing displacements frequently damage ski infrastructure, agricultural buildings, a golf course and the national road SS 244. Surface and subsurface measurement since 1997 have shown a spatially varying movement velocity which ranges from a few $\mathrm{cm} /$ year in 

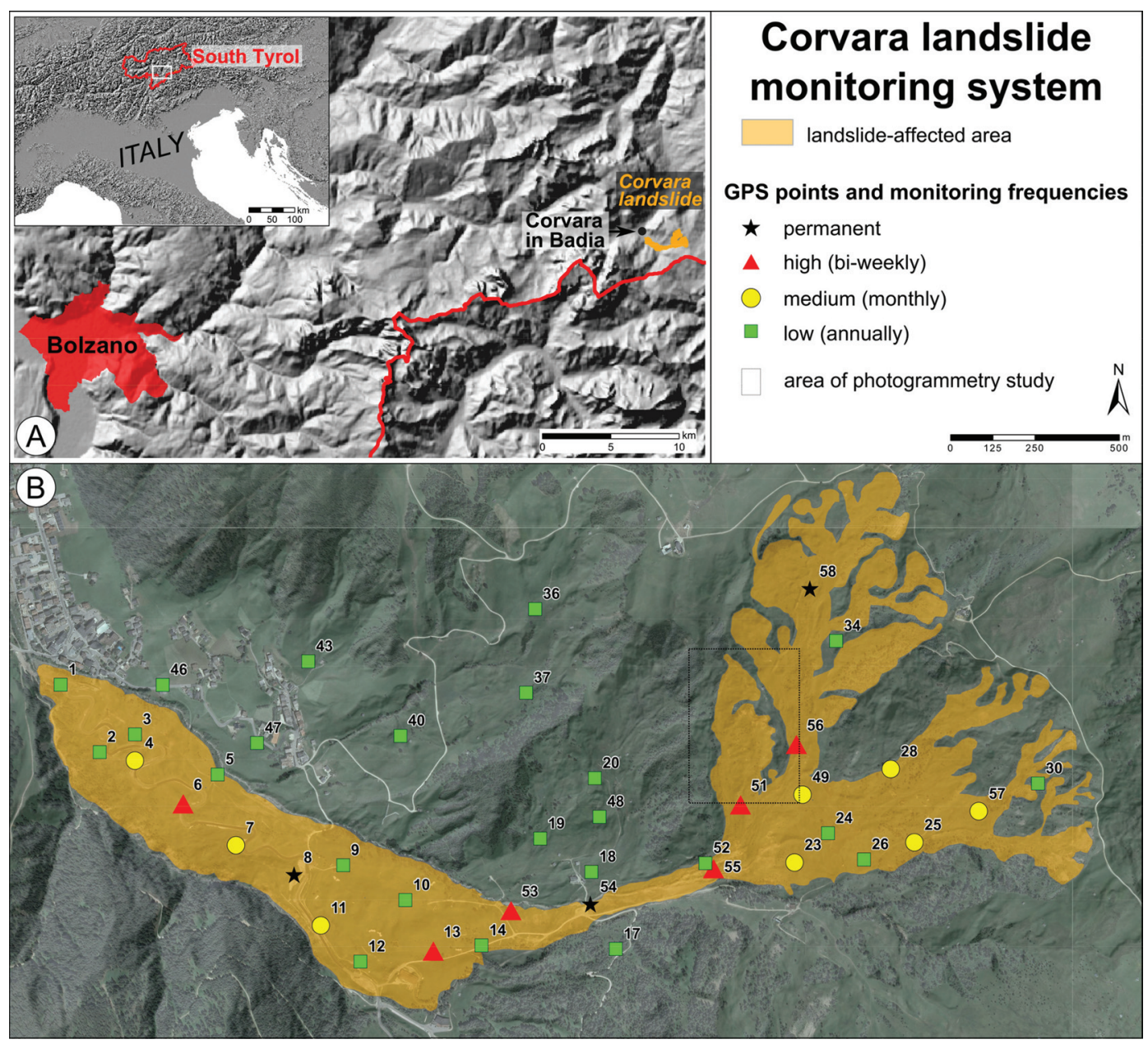

Figure 1. Corvara landslide (A) location in South Tyrol; (B) monitoring system and area of photogrammetry study (dotted black rectangle).

the toe zone, and exceeds $20 \mathrm{~m} /$ year in the most active track and source zones. Phases of higher landslide velocities have been caused primarily by periods of prolonged rainfall and snow-melting, and recently also to the accumulation of large quantities of snow (Corsini et al., 2015). In 2013 and 2014, movements in the source and track zone have been higher than in previous years, reaching tens of metres and causing significant topographic changes.

\section{METHODS}

\subsection{Flight campaign}

For our study, we selected one branch of Corvara landslide that based on geomorphological field evidence has been very active in recent months (see Figure 2). Due to the lack of monitoring activities in this part of the landslide, the details of activation and displacement are not known. The area of our investigations extended for approximately $300 \mathrm{~m} \times 500 \mathrm{~m}$ and has a difference in elevation of approximately $90 \mathrm{~m}$.

Our UAV-based study utilised an octocopter produced by SoLeon $\mathrm{GmbH}$ with a payload of $1550 \mathrm{~g}$. A flight speed of $1 \mathrm{~m} / \mathrm{s}$ was selected and photos with three different exposures were taken every 2 seconds utilising a Ricoh GR 16.2 Megapixels camera. Each of the five flights had a duration of approximately 20 minutes and followed pre-defined GPS coordinates in an elevation of approximately $70 \mathrm{~m}$ above ground. Patterned Ground Control Points (GCP) consisting of laminated plastic sheets with 

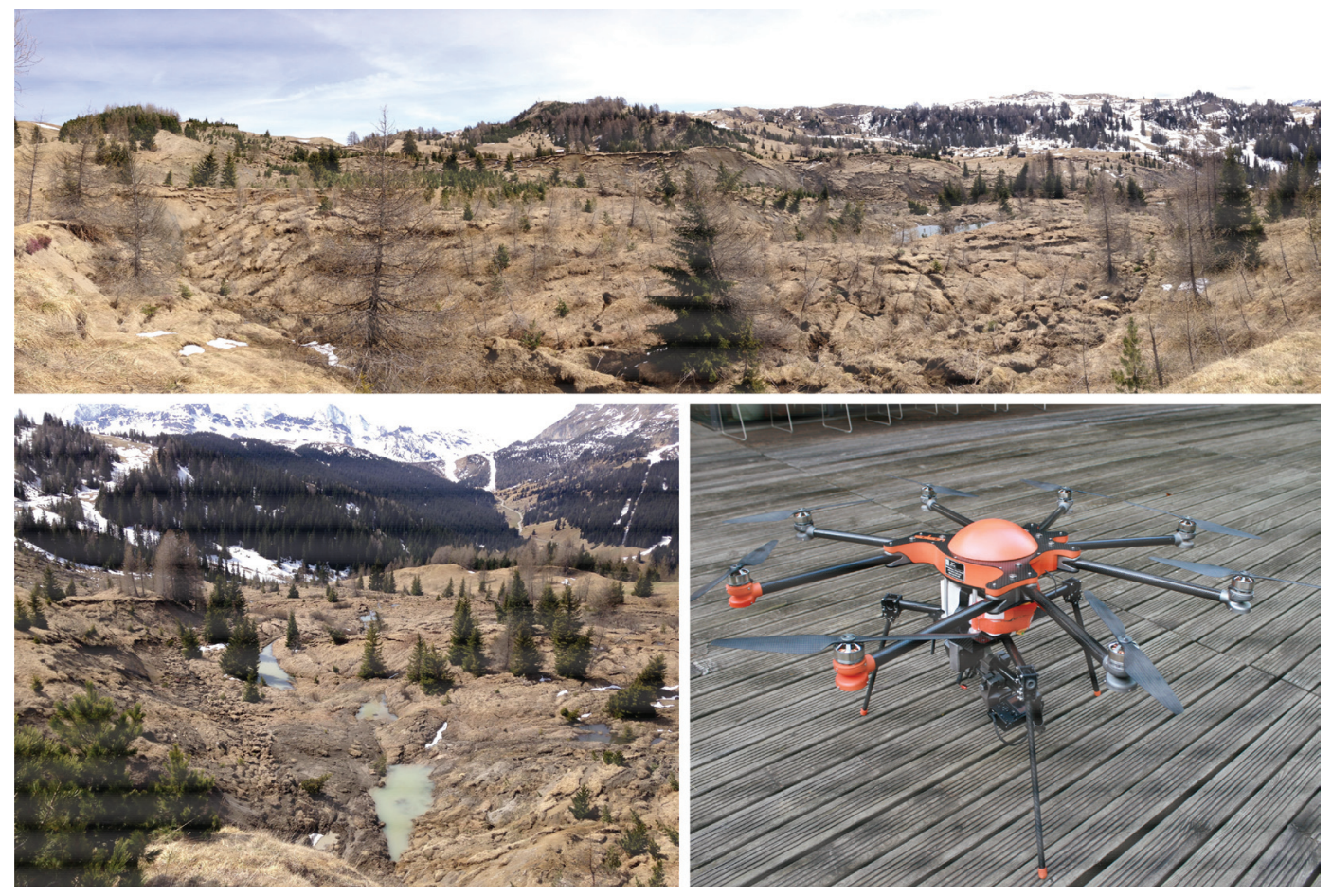

Figure 2. Field impressions from the study site and UAV used in this study.

dimensions of $40 \times 40 \mathrm{~cm}$ were placed in the flight area and measured with two Leica GNSS GS10 for at least 5 minutes each. Some 22 GCP were used for stitching the data of the different flights and for georeferencing of the resulting orthophoto and DSM.

\subsection{Data processing}

GPS data was further processed using Leica GeoOffice software and utilising data from the reference station at Piz La Ila, located at a distance of approximately $2 \mathrm{~km}$. Data from the reference station was used to improve the localisation of two of the permanent GPS points (i.e. points 8 and 54), and was followed by retrieval of the coordinates for the measured GCPs. To be able to compare the DSM with existing data, all coordinates had to be corrected to account for the differing geoid model (orthometric vs. ellipsoid). We used the elevation correction factor of $51.58 \mathrm{~m}$ proposed by the Geodetic Office of the Province of Bolzano. At a later stage, it was found that the elevations of the acquired data still differed from the elevations of the official LiDAR terrain model. This is most likely related to differences in the DEMs' spatial resolution as well to different vegetation heights. Aiming to decrease the elevation difference of non-landslide-affected areas, and a further elevation correction of $50 \mathrm{~cm}$ was applied.

The processed GPS data were exported and used to georeference the point cloud and high-resolution images in the Pix4D software. Mosaicking of the aerial imagery was performed through a seamless method in ERDAS using smooth an image fusion algorithm, image histogram equalisation and contrast control. The resulting merged orthophoto as well as a unified point cloud that was directly converted to a DSM were exported and further analysed in ArcGIS. The DSM resolution was reduced to $2.5 \mathrm{~m}$ to match the resolution of the available terrain data (LiDAR-based DSM from 2006), and a DoD (DEM of difference) was calculated using the RasterCalculator toolbox (ARCMAP 10.3). Based on the acquired high detail DSM and the orthophoto, the current landslide borders were mapped and the resulting polygon was used to clip the DoD.

\section{RESULTS}

In the aftermath of recent reactivations of the parts of the Corvara landslide, the UAV survey was conducted as part of a complex study to explore 
the displacement fields of one of the most active landslide parts. The UAV-based photogrammetric campaign performed in August 2015 allowed us to determine landslide enlargements, topographical changes and displacement rates that have occurred over the last 9 years.

After a one day field campaigns, processing of photogrammetry data required a processing time of more than 2 days. The final orthophoto was merged from 2033 calibrated and geo-located images, has an average ground sampling distance of $1.5 \mathrm{~cm}$ and the mean RMS error was assessed to be $6.3 \mathrm{~cm}$. The point clouds generated from the aerial imagery included more than 200 million points and were transferred to a DSM with a pixel size of $1.5 \mathrm{~cm}$. In total, the orthophoto and the DSM cover an area of around 13 ha (Fig. 3A). GCP positioning quality totalled approximately $11 \mathrm{~cm}$ (position and height), however, due to the different geoid models (ellipsoid vs. orthometric), a higher inaccuracy in elevation has to be assumed.

Results of DoD analyses computed between our $2015 \mathrm{DSM}$ and the $2.5 \mathrm{~m}$ resolution airborne LiDAR DSM of 2006 are presented in Figure 3.

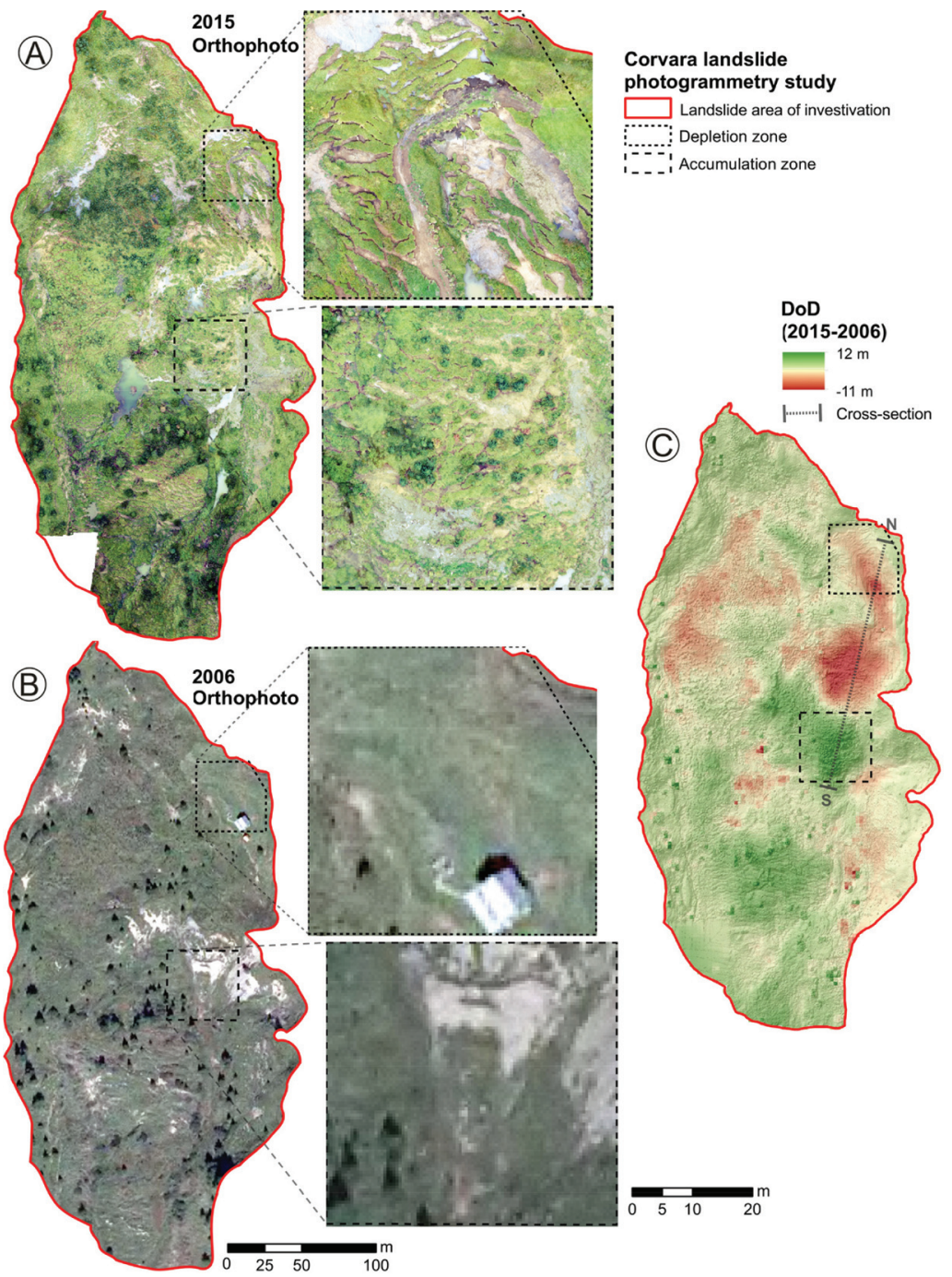

Figure 3. Photogrammetry study area. (a) UAV Orthophoto of 2015. (B) Orthophoto of 2006. (C) DoD between 2006 and 2015. 


\subsection{Orthophoto}

The 2015 orthophoto provided by the UAV survey is characterised by a very high spatial resolution and allows for the detection and mapping of surface features in an unprecedented level of detail (see Fig. 3a). The comparison of the UAV-based orthophoto to imagery previous acquired (e.g. 2006, 2008 and 2011; all acquisitions were carried out spring/summer of the repsective years) show changes in vegetation cover and reveal the activity of the landslide. At the crown area (uppermost zoomed picture), a hut was visible in 2006 (Fig. 3b) while it does not exist anymore in 2015 (Fig. 3a) due to landslide reactivation. In the landslide body (zoomed picture in the middle of area; Fig 3), scarps and debris were observed in 2006 while nowadays the hummocky-shaped geomorphology is characterised by some accumulation of soil material and growing vegetation at the previously denudated scarps. Some ponds and accumulations of mud are also visible in the middle and lower parts on the 2015 orthophoto.

\subsection{DoD}

The DoD shows topographic changes (i.e. positive or negative values corresponding to gains and losses of material) located at different locations inside the photogrammetry study area (Fig. 3C). In the northern zone, change values are negative or barely positive while in the southern area reaching the main Corvara landslide tongue, values are mainly positive or close to zero. Red spots are observed along the eastern scarp whereas directly downstream (to the South), a green circular spot is distinguished (see polygons in dotted lines, Fig. 3c). Circular spots of greenish colours can highlight trees while zones lightly coloured in red can correspond to pounds. The maximal positive displacement reaches $12 \mathrm{~m}$ and the maximal negative accumulation reaches $11 \mathrm{~m}$ over the 9-year period. Negative DoD values at the crown area (1940 $\mathrm{m}$ asl) and positive values at the middle part of the landslide body (1910 $\mathrm{m}$ asl) are clearly visible in the N-S cross-sectional profile represented in Figure 4. Two depletion zones (deep graben) of $25 \mathrm{~m}$ and $65 \mathrm{~m}$ wide are observed with a maximal value reaching $10 \mathrm{~m}$ and a $40 \mathrm{~m}$ large accumulation zone corresponds to some maximal values around $6-7 \mathrm{~m}$.

\subsection{Landslide kinematics}

The results reveal a substantial increase of the landslide-affected area which progressively enlarged on the northern and northwestern part of the investigated branch of the active Corvara landslide.

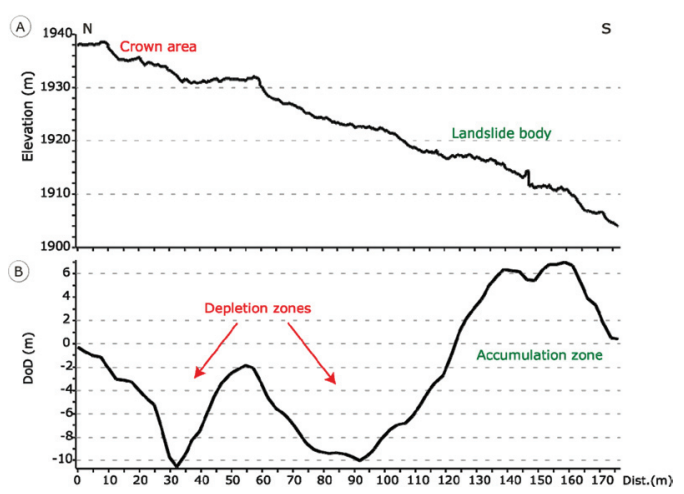

Figure 4. Cross-section to study landslide displacement patterns. (A) Elevation with location of crown area and landslide body and (B) DoD showing depletion and accumulation zones.

The enlargement of the landslide can best be observed at the hut (highlights in Figure 3) which was still present in 2006 but was destroyed due to retrogressive landslide activity. The enlargement in this part of the landslide totals approximately $30 \mathrm{~m}$. A comparison to other orthophotos from 2008 and 2011 revealed that the described enlargement took place after 2011, i.e. within a period of 4 years or less. This would relate to annual rate of up to $8 \mathrm{~m}$, however, as the orthophoto analyses shows, the retrogressive enlargements show a strong temporal variability.

Inside the active landslide, vertical elevation changes reach up to $70 \pm 6.3 \mathrm{~cm} \mathrm{yr}-1$ and $110 \pm 6.3 \mathrm{~cm}$ yr-1 in accumulation and depletion areas, respectively.

\section{DISCUSSION}

The UAV survey allowed us to acquire data with a very high level of detail but require careful interpretation. In contrast to LiDAR terrain models, our photogrammetry approach is not able to produce bare earth terrain models but also includes vegetation. This may lead to false interpretation regarding the magnitude of topographical changes. During the time of our flight campaign (i.e. August 2015), the grassy vegetation that covers many parts of the study site had a height of up to $50 \mathrm{~cm}$. Moreover, several bushes and trees are included in the DSM which necessarily produces inaccuracies and errors. In this study, topographical changes are in many cases substantially exceeding the height of vegetation This makes an exact quantification of topographic changes difficult, however, overall displacement patterns and areas 
with the highest activity can be determined with a high degree of certainty.

It has to be kept in mind that a comparison of any multi-temporal DTM or DSM data sets is only able to reveal changes of elevation. If landslide material is just being transported through a segment of the landslide, something that is not necessarily related to a change of topographic height, the applied methodology is not able to detect this.

\section{CONCLUSIONS}

The results allow for a representation of topography and the detection and mapping of geomorphological features that was not possible before. They provide a valuable information on the landslide displacement patterns over an area of around 13 ha. Recorded vertical elevation change rates reach up to $70 \mathrm{~cm}$ yr-1 and $110 \mathrm{~cm}$ yr-1 in accumulation and depletion areas considering a $\pm 6.3 \mathrm{~cm}$ uncertainty. Furthermore, the UAV-based study proved to be a good addition to our ongoing DInSAR processing activities which has limitations for measuring displacements in a southward direction and is only able to detect landslide velocity estimations for the installed corner reflectors. In conclusion, photogrammetric surveys can be evaluated as a useful methodology and repeated measurements will be continued at least on an annual basis. This will also allow for a more detailed comparison of the data; downscaling of the acquired DSMs will not be required and full advantage can be taken of the centimeter-scale resolution. Further investigation will be carried out using different camera setups, e.g. thermal and infrared. Additional ground-based photogrammetry surveys are planned for areas around the corner reflectors (tracked by DInSAR). Moreover, the installation of a fixed camera is also planned which can be used to daily follow the landslide displacements.

\section{REFERENCES}

Borgatti, L., Soldati, M. 2010. Landslides as a geomorphological proxy for climate change: A record from the Dolomites (northern Italy). Geomorphology 120, 56-64.

Corsini, A., Mulas, M., Marcato, G., Chinellato, G., Mair, V. 2015. Acceleration of large active earthflows triggered by massive snow accumulation events: evidences from monitoring the Corvara landslide in early 2014 (Dolomites, Italy), in: EGU2015-7357. Presented at the European Geoscience Union General Assembly 2015, Vienna, Austria.

Corsini, A., Pasuto, A., Soldati, M., Zannoni, A. 2005. Field monitoring of the Corvara landslide (Dolomites, Italy) and its relevance for hazard assessment. Geomorphology 66, 149-165.

Delacourt, C. 2004. Velocity field of the "La Clapière" landslide measured by the correlation of aerial and QuickBird satellite images. Geophys. Res. Lett. 31. doi:10.1029/2004GL020193.

Guzzetti, F., Mondini, A.C., Cardinali, M., Fiorucci, F., Santangelo, M., Chang, K.-T. 2012. Landslide inventory maps: New tools for an old problem. Earth-Sci. Rev. 112, 42-66. doi:10.1016/j. earscirev.2012.02.001.

Jaboyedoff, M., Oppikofer, T., Abellán, A., Derron, M.-H., Loye, A., Metzger, R., Pedrazzini, A. 2010. Use of LIDAR in landslide investigations: a review. Nat. Hazards 61, 5-28. doi:10.1007/s11069-010-9634-2.

Mulas, M., Petitta, M., Corsini, A., Schneiderbauer, S., Mair, F.V., Iasio, C. 2015. Long-term monitoring of a deep-seated, slow-moving landslide by mean of $\mathrm{C}$-band and $\mathrm{X}$-band advanced interferometric products: the Corvara in Badia case study (Dolomites, Italy). ISPRS-Int. Arch. Photogramm. Remote Sens. Spat. Inf. Sci. XL-7/W3, 827-829. doi:10.5194/ isprsarchives-XL-7-W3-827-2015.

Schädler, W., Borgatti, L., Corsini, A., Meier, J., Ronchetti, F., Schanz, T. 2014. Geomechanical assessment of the Corvara earthflow through numerical modelling and inverse analysis. Landslides. doi:10.1007/s10346-014-0498-5. 